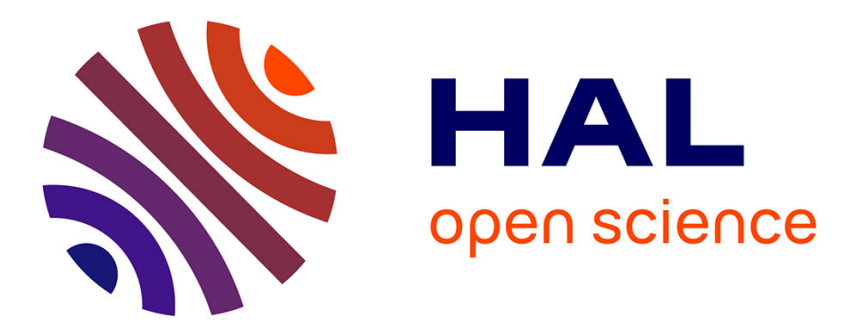

\title{
On the modelling of low to medium velocity impact onto woven composite materials with a $2 \mathrm{D}$ semi-continuous approach
}

\author{
Florian Pascal, Pablo Navarro, Steven Marguet, Jean-François Ferrero
}

\section{To cite this version:}

Florian Pascal, Pablo Navarro, Steven Marguet, Jean-François Ferrero. On the modelling of low to medium velocity impact onto woven composite materials with a $2 \mathrm{D}$ semi-continuous approach. Composite Structures, 2015, 134, pp.302-310. 10.1016/j.compstruct.2015.08.067 . hal-01878084

\section{HAL Id: hal-01878084 https://hal.science/hal-01878084}

Submitted on 12 Jun 2019

HAL is a multi-disciplinary open access archive for the deposit and dissemination of scientific research documents, whether they are published or not. The documents may come from teaching and research institutions in France or abroad, or from public or private research centers.
L'archive ouverte pluridisciplinaire HAL, est destinée au dépôt et à la diffusion de documents scientifiques de niveau recherche, publiés ou non, émanant des établissements d'enseignement et de recherche français ou étrangers, des laboratoires publics ou privés. 


\title{
On the modelling of low to medium velocity impact onto woven composite materials with a $2 \mathrm{D}$ semi-continuous approach
}

\author{
F. Pascal ${ }^{*}$, P. Navarro, S. Marguet, J-F. Ferrero \\ Université de Toulouse, Institut Clément Ader, FRE CNRS 3687, UPS/INSA/ISAE/Mines Albi, 3 rue Caroline Aigle, 31400 Toulouse, France
}

\begin{abstract}
A B S T R A C T
An explicit finite element modelling of the 5-harness satin woven composite material is proposed in this paper. It is based on the semi-continuous approach which consists in separating fibre and matrix mechanical behaviours. The bundles are modelled with rod elements and a specific damageable shell element is used to stabilize this truss structure. As the woven pattern geometry plays a key role in damage initiation and propagation, a modification has been made in the failure strain of the rods located at the crimp regions where warp and weft yarns cross each other.

The method has been implemented into the explicit finite element code RADIOSS and is computationally efficient to model low to medium velocity impact $(1-200 \mathrm{~m} / \mathrm{s})$ at the structure scale. The modelling strategy is validated by representing a drop weight test and an oblique impact test and provides good prediction of impact force history and damage size and location.
\end{abstract}

\section{Introduction}

This article deals with the modelling of woven composite laminates under impact loading. Indeed, a modelling strategy that accounts for the internal structure of 5-harness satin woven composite plies is investigated.

In the field of aeronautical designing, 5-harness satin carbon/ epoxy woven composites are increasingly used for the manufacturing of the structure. A minor weakness in this part can have catastrophic consequences. Thus, understanding and predicting impact damage mechanisms in this material is required.

The behaviour of composite structures under impact loading has been widely studied. Comprehensive reviews by Abrate [1,2] describe impact damage mechanisms for a large range of composite materials. Typically, cracks in the resin, delamination and fibre breakages can be observed.

Damage mechanisms in composite materials highly depend on its structure. In the specific field of woven laminate composites, the characteristic structure of the plies leads to complex behaviour [3-5]. Indeed, even for static loadings, the damage first accumulates in the crimp region where the yarns cross each other. Local behaviour has an important influence on the global response, damage initiation and propagation. For impact loading, Nilakantan

\footnotetext{
* Corresponding author.

E-mail address: florian.pascal@univ-tlse3.fr (F. Pascal).
}

et al. [6] showed that the local variation of the strength of the yarns can have a major effect on the impact response of woven fabrics.

Three levels of representation can be distinguished for the modelling strategies of impacts on woven composite laminates. The first modellings are build at a macroscopic scale. Customized damageable energy based material laws are used with FEM [7-13]. In these models, the woven fabric is represented using homogenised shell elements. The second level of representation is the bundle scale. Navarro et al. [14-16] have developed a semi-continuous modelling where the bundles of fibres are represented with rod elements stabilized with specific damageable shell elements. The idea is to model the fact that when the resin is fully damaged, the woven fabric behaves as a discrete truss structure. This strategy provides a good representation but cannot represent the local damages due to the weaving pattern. The third strategy is at the pattern scale. The models are based on properties calculated from a deforming unit cell. This unit cell is generally very detailed [17-20]. This strategy is able to represent the local strain and stress fields due to the weaving pattern, but it can hardly be used for large structures.

In this paper, an extension of the semi-continuous approach presented in [15] is described. The modelling is modified in order to take into account the weaving pattern geometry. The properties of the rods are adapted to represent local strain concentrations.

In the first part, the modelling strategy is presented. The damage law used for the specific shell elements and the failure behaviour of the rods are described. Then a parameter sensitivity study is 
proposed. Finally the strategy is validated by comparing with drop weight normal impact tests and gas gun oblique impact tests.

The presented approach is accurate enough to predict the size and the shape of the damage. The mechanisms observed experimentally leading to the final rupture are well represented.

\section{Modelling strategy}

The proposed modelling strategy for the woven composite laminate extends previously published models that use a "semicontinuous approach" [14-16]. In this model, the ply bundles are represented by $1 \mathrm{D}$ rod elements connected by nodes to the 4 edges of a quadrilateral shell element (Fig. 1). The element length respects the woven fabric pattern i.e. the distance between two bundles. For delamination modelling, each ply are connected with a shell-to-shell interface element with a cohesive law detailed in [16]. This strategy allows to both represent the continuous elastic behaviour of the undamaged skin and the discrete behaviour of the woven ply when resin is damaged and bundle of fibres are in a non-stabilized state.

This type of modelling offers good comparison with experimental data regarding drop weight test and gas gun test. Nevertheless, in order to simulate more accurately experimental observations, two main improvements have been made:

- The shell damage formulation has been changed in order to capture a more accurate damage scenario of the resin during impact.

- The maximum strain to failure of the rods is now dependent on their physical positions in the woven pattern. It allows to take into account the strain concentrations due to woven pattern geometry.

\subsection{Shell damage model}

In this subsection, the finite element formulation and the damage variables used for the shell are presented.

\subsubsection{Formulation used}

The developed shell element is based on Batoz Q4 $\gamma 24$ shell formulation [21] with four Gauss integration points and reduced integration for in-plane shear (Fig. 1). No hourglass control is needed for this shell.

Due to the particular modelling strategy, the shell element has a membrane stiffness different from the bending one. In membrane loading, the shell is regarded as matrix material whereas in bending and transverse shear loadings, the rods do not have any influence so the shell stiffness is assimilated to the homogenised ply. Hence, the distinction is made by differentiating the values of the corresponding elastic modulus, $E^{m}$ for membrane, $E^{b}$ for bending and $G^{s}$ for out-of-plane shear.

\subsubsection{Damage variable}

In order to better understanding the matrix damage scenario during an impact loading, a specific experimental set up has been made. A drop weight test impact has been performed onto a single ply of carbon-epoxy 5-harness satin woven fabric. A high-speed camera was used to film the bottom face of the plate. Besides, the face was covered with a very thin layer of white paint to emphasise the matrix cracks. All impact tests have led to a fracture shape similar to Fig. 2. Every crack is oriented along a carbon bundle and matches exactly with the 5-harness satin weave pattern. Further details on the experimental set up and results will be presented in Section 4.1.1.

The main assumption about damage mechanism is as follows: when resin is damaged, the local structure is lost and the ply bending stiffness is affected. The bundles are temporally and locally relaxed until, carrying all the loads, they fail in tension.

Numerically, the idea is to capture the oriented cracks observed experimentally just before the first fibre ruptures. Thus, matrix failure is modelled with two damage variables for each local fabric direction namely $d_{1}$ and $d_{2}$. They are functions of the energy release rates $Y_{1}$ and $Y_{2}$ calculated from the resin material properties. Then, in order to model the complete loss of bending stiffness, this two damage variables degrade both membrane (resin) and out-of-plane (homogenised woven) moduli. This can be summarised as:

$$
\begin{aligned}
& \text { - } d_{1}=f\left(E^{m}\right) \text { affects } E_{1}^{m}, E_{1}^{b} \text { and } G_{13}^{s} \\
& \text { - } d_{2}=f\left(E^{m}\right) \text { affects } E_{2}^{m}, E_{2}^{b} \text { and } G_{23}^{s}
\end{aligned}
$$

Damage evolution is given by:

$$
d_{i}=\left\{\begin{array}{cc}
\frac{\left\langle\sqrt{Y_{i}}-\sqrt{Y_{0}}\right\rangle_{+}}{\sqrt{Y_{c}}} & \text { if } d_{i}<1 \\
1 & \text { otherwise }
\end{array} \quad(i=1,2)\right.
$$

where $Y_{0}$ controls the damage initiation, $Y_{c}$ the damage evolution and the energy release rate $Y_{i}$ regarding the local direction $i$ is given by:

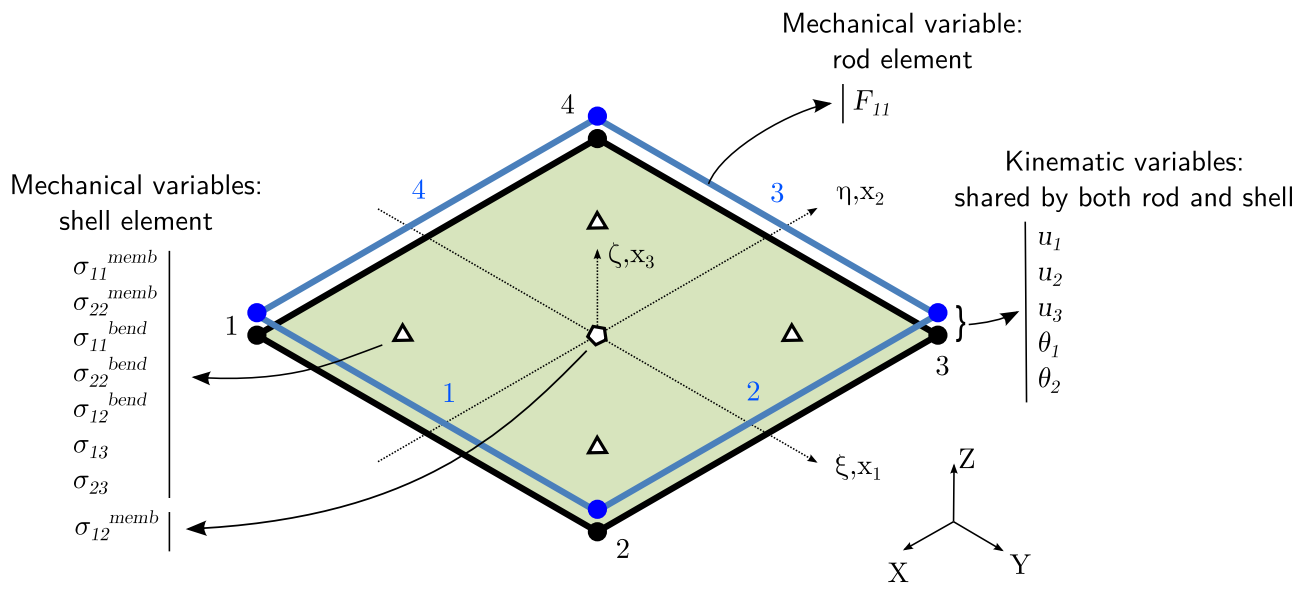

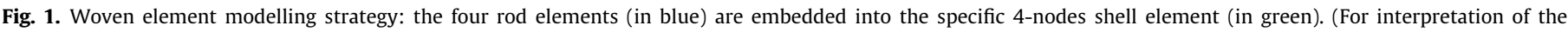
references to colour in this figure legend, the reader is referred to the web version of this article.) 


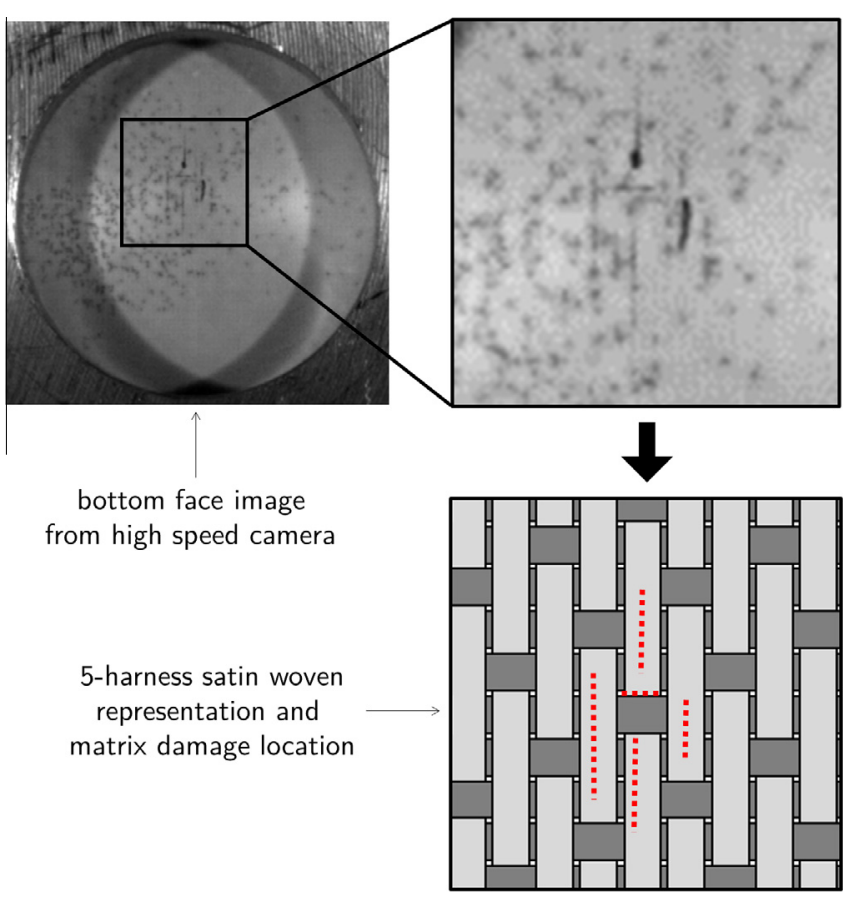

Fig. 2. First resin failure observed on a single ply plate under drop weight test.

$Y_{i}=\sup _{t \leqslant \tau}\left(\frac{E^{m}}{2\left(1-v^{2}\right)}\left\langle\varepsilon_{i i}^{m}+\varepsilon_{i i, \max }^{b}\right\rangle_{+}^{2}\right) \quad(i=1,2)$

with $\left\langle\varepsilon_{i i}^{m}+\varepsilon_{i i, \max }^{b}\right\rangle$, which denotes the positive part of the sum of the membrane and the maximum positive bending strains in local direction $i=1,2$ and $v$ the matrix in-plane elastic Poisson's ratio.

Hence, $d_{1}$ and $d_{2}$ manage all the mechanical variable of the shell except for the in-plane shear modulus $G_{12}$. Indeed, it has been observed experimentally that pseudo-plasticity was the predominant phenomenon concerning in-plane shear. Thus, a plastic strain $\gamma_{12}^{p}$ has been introduced. A classic elastic prediction and plastic correction based on a Newton-Raphson iterative scheme has been implemented. The elastic field is defined by:

$f=\left|\sigma_{12}\right|-K_{\text {plas }}\left(\varepsilon_{12}^{p}\right)^{\beta}-\sigma_{0}$,

where $\sigma_{12}$ is the in-plane shear stress, $\sigma_{0}$ the plastic strength, $\varepsilon_{12}^{p}$ the plastic shear strain and $\left(K_{\text {plas }}, \beta\right)$ are material parameters defining the plastic hardening law.

Besides, a third independent damage variable $d_{12}$ has been implemented to model the final in-plane shear rupture. Its evolution is driven by a brittle law:

$d_{12}=\left\{\begin{array}{ll}0 & \text { if } \gamma_{12}^{p}<\gamma_{\max }^{p} \\ 1 & \text { if } \gamma_{12}^{p} \geqslant \gamma_{\max }^{p}\end{array}\right.$,

where $\gamma_{\max }^{p}$ is the in-plane shear plastic strain to rupture.

\subsubsection{Stress strain relationship with damage}

The membrane, bending and shear stress-strain relationships are defined by:

$$
\begin{aligned}
& \left\{\begin{array}{l}
\sigma_{11}^{m} \\
\sigma_{22}^{m}
\end{array}\right\}=\frac{1}{1-v_{12} v_{21}}\left[\begin{array}{cc}
E_{1}^{m} & v_{21} E_{1}^{m} \\
v_{12} E_{2}^{m} & E_{2}^{m}
\end{array}\right]\left\{\begin{array}{l}
\varepsilon_{11}^{m} \\
\varepsilon_{22}^{m}
\end{array}\right\} \\
& \left\{\begin{array}{l}
\sigma_{11}^{b} \\
\sigma_{22}^{b}
\end{array}\right\}=\frac{1}{1-v_{12} v_{21}}\left[\begin{array}{cc}
E_{1}^{b} & v_{21} E_{1}^{b} \\
v_{12} E_{2}^{b} & E_{2}^{b}
\end{array}\right]\left\{\begin{array}{l}
\varepsilon_{11}^{b} \\
\varepsilon_{22}^{b}
\end{array}\right\}
\end{aligned}
$$

$$
\left\{\begin{array}{l}
\sigma_{12} \\
\sigma_{13} \\
\sigma_{23}
\end{array}\right\}=\left[\begin{array}{ccc}
G_{12}^{*} & 0 & 0 \\
0 & G_{13} & 0 \\
0 & 0 & G_{23}
\end{array}\right]\left\{\begin{array}{c}
\gamma_{12}-\gamma_{12}^{p} \\
\gamma_{13} \\
\gamma_{23}
\end{array}\right\}
$$

with:

$$
\begin{cases}E_{i}^{m}=\left(1-H_{i} d_{i}\right) E^{m} \quad(i=1,2) \\ E_{i}^{b}=\left(1-H_{i} d_{i}\right) E^{b} \quad(i=1,2) \\ v_{12}=\left(1-H_{1} d_{1}\right) v \\ v_{21}=\left(1-H_{2} d_{2}\right) v \\ G_{12}^{*}=\left(1-d_{12}\right) G_{12} \\ G_{i 3}=\left(1-H_{i} d_{i}\right) G^{s} \quad(i=1,2)\end{cases}
$$

where $E_{i}^{m}$ and $E_{i}^{b}$ are respectively the damaged membrane and bending moduli in local direction $i,\left(v_{12}, v_{21}\right)$ the damaged inplane Poisson's ratios, $G_{i 3}$ the damaged out-of-plane shear moduli and $H_{i}$ is defined by:

$H_{i}=0 \quad$ if $\quad\left(\varepsilon_{i i}^{m}+\varepsilon_{i i, \max }^{b}\right)<0, \quad H_{i}=1 \quad$ otherwise.

\subsection{Rod failure}

The bundle rupture is assumed to be brittle in tension. Therefore, a classic maximum tensile strain criterion is used for the rupture of the rods. In order to avoid numerical instabilities, when the maximum strain criterion is reached, rod normal force is smoothly decreased by the use of a characteristic time $\tau$ as follow:

$F_{11}=F_{11}^{*}\left(1-\exp \frac{t^{*}-t}{\tau}\right)$

where $t^{*}$ is the exact time at which the criterion is reached and $F_{11}^{*}$ the force stored at time $t^{*}$. $\tau$ has been taken equal to $1 \mu \mathrm{s}$ which corresponds to the best compromise between stability and parameter sensitivity to the results. The compression failure mechanism i.e. kink band phenomenon is neglected in our study.

The weave pattern geometry is demonstrated by several authors to be a key factor in damage initiation and propagation. Melro et al. [18] illustrate this phenomenon with a micro-mechanical modelling of a representative unit-cell of a 5-harness satin woven fabric. Fig. 3(a) shows the yarn transverse damage during a uni-axial tensile load. The authors highlight that damage first tends to accumulate in the crimp region of the warp where the yarns cross each other. Likewise, Daggumati et al. [5] observed from DIC measurements that maximum local longitudinal strain on surface of a 5-harness satin woven loaded in tension occurred at the centre of the weft yarn at the yarn crimp location (Fig. 3(b)).

As a result of the woven pattern influence on strain concentrations and damage initiation, an improvement has to be made in the modelling strategy to be in better agreement with the experimental observations. The main issue is that the 2D modelling cannot allow to catch naturally this stress concentrations. However, a new approach has been adopted and consists in lowering the tensile failure strain of the rods located at the crimp regions. The idea is to localise the rupture at this specific points without modelling the waviness of the yarns in those regions. Fig. 4 shows a schematic representation of the carbon epoxy woven fabric on study superimposed with the adopted FE meshing. Three types of rods are thus distinguished: warp yarns at the crimp location, weft yarns at the crimp location and the others (regardless of warp or weft yarn). 


\section{Implementation and identification}

\subsection{Implementation}

The developed woven element is implemented into the explicit finite element code RADIOSS (Altair Hyperworks) through a 4nodes user element (SUSER Fortran subroutine). The four nodes are used to model both the shell element and the four rod

(a)
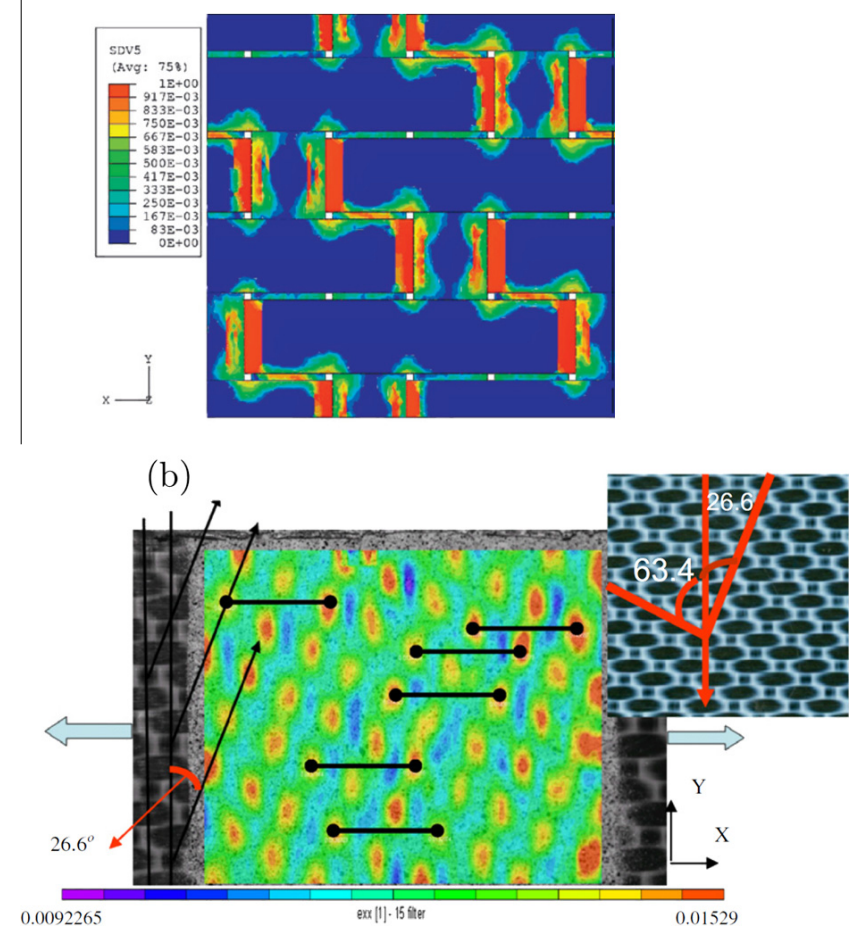

Fig. 3. Damage location for uniaxial tensile load on a 5-harness satin woven fabric: (a) numerical transverse damage in yarns [18]; (b) experimental longitudinal surface strain contours [5].

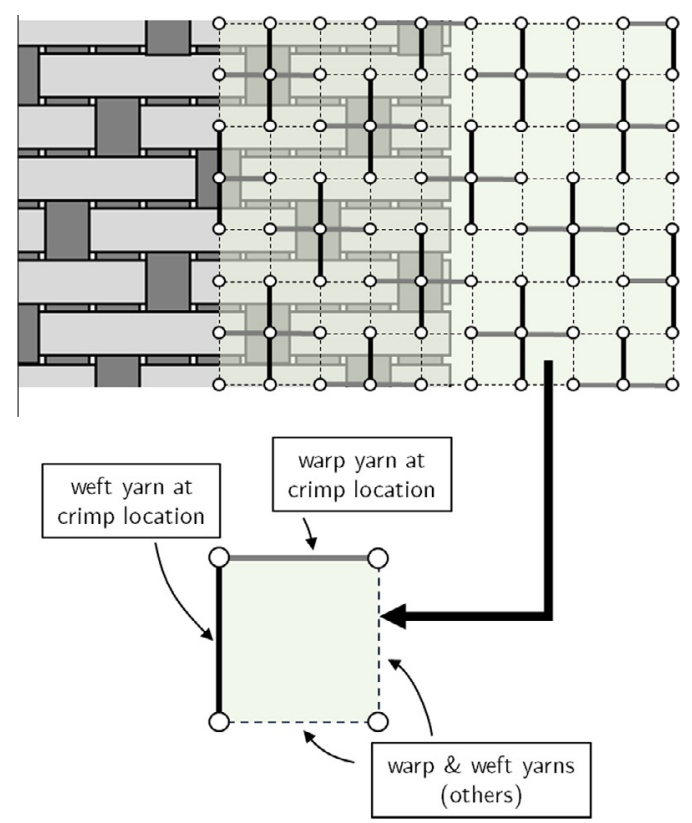

Fig. 4. Introduction of the 5-harness satin weave pattern into the modelling strategy.

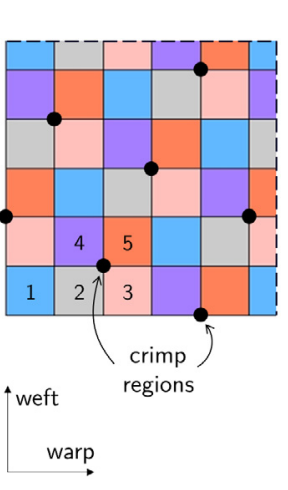

\begin{tabular}{|c|c|c|c|c|c|}
\hline \multicolumn{6}{|c|}{ rod3 } \\
\hline 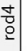 & $\begin{array}{c}\text { Prop } \\
\mathrm{N}^{\circ}\end{array}$ & $\underline{\operatorname{rod} 1}$ & rod 2 & rod 3 & rod 4 \\
\hline \multicolumn{6}{|c|}{ rod1 } \\
\hline & ו & $\begin{array}{l}\text { other } \\
\text { (warp) }\end{array}$ & $\begin{array}{l}\text { other } \\
\text { (weft) }\end{array}$ & $\begin{array}{c}\text { other } \\
\text { (warp) }\end{array}$ & $\begin{array}{l}\text { other } \\
\text { (weft) }\end{array}$ \\
\hline 1 & $\begin{array}{c}2 \\
--- \\
\end{array}$ & $\begin{array}{l}\text { other } \\
\text { (warp) }\end{array}$ & $\begin{array}{c}\text { crimp } \\
\text { weft }\end{array}$ & $\begin{array}{l}\text { crimp } \\
\text { warp }\end{array}$ & other \\
\hline & $\begin{array}{ll}3 & 1 \\
- & -\end{array}$ & $\begin{array}{l}\text { other } \\
\text { (warp) }\end{array}$ & $\begin{array}{l}\text { other } \\
\text { (weft) }\end{array}$ & $\begin{array}{l}\text { crimp } \\
\text { warp }\end{array}$ & $\begin{array}{c}\text { crimp } \\
\text { weft }\end{array}$ \\
\hline & 4 & $\begin{array}{l}\text { crimp } \\
\text { warp }\end{array}$ & $\begin{array}{c}\text { crimp } \\
\text { weft }\end{array}$ & $\begin{array}{l}\text { other } \\
\text { (warp) }\end{array}$ & $\begin{array}{l}\text { other } \\
\text { (weft) }\end{array}$ \\
\hline & 5 & $\begin{array}{l}\text { crimp } \\
\text { warp }\end{array}$ & $\begin{array}{l}\text { other } \\
\text { (warp) }\end{array}$ & $\begin{array}{l}\text { other } \\
\text { (weft) }\end{array}$ & $\begin{array}{c}\text { crimp } \\
\text { weft }\end{array}$ \\
\hline
\end{tabular}

Fig. 5. Meshing of a 5-harness satin woven fabric.

elements. Therefore, the rod elements do not need an additional meshing work since they are embedded into the user element formulation. Besides, the section of each rod is half the real bundle one since each bundle is represented with two rods (one from each adjacent element) which are superimposed on each other. Finally, the rod tensile failure strain depends on the position of the user element in the woven pattern and is defined by a user property number.

In the case of a 5-harness satin weave modelling, 5 different properties of the user element are needed to differentiate the three types of rods and to take into account their positions into the woven pattern. Fig. 5 shows a meshing of a 5-harness satin woven fabric and the pattern of element properties used. Property number 1 defines the woven element which is not located at the crimp region. The four rods see their failure strain unchanged. The four other properties (2-5) refer to the elements located at the crimp region where the yarns cross each other. Each one of them have 2 rods representing a crimped yarn (warp and weft). Their failure strain can thus be changed via the user property parameters.

\subsection{Identification and strain-to-failure study}

The material parameters of the 5-harness satin carbon-epoxy woven fabric have been identified with the same approach that was used in [14] which was concerned with the 8-harness satin glass-epoxy woven fabric. The matrix (and membrane) modulus $E^{m}$ is a material property given by the fabrics manufacturer. Then, quasi-static and dynamic tests on $(0 / 90)^{\circ}$ and $\pm 45^{\circ}$ oriented specimens have been performed. The other parameters are thus determined with a reverse engineering method which consists in minimising the difference between experimental and computed load/displacement curves. The evolution of the damage variables $\left(d_{1}, d_{2}\right)$ have been calculated from static and dynamic indentation tests. The identified parameters for the shell elements are given in Table 1.

Concerning the parameters that lead the fibre ruptures, a qualitative study of their influence on the final fracture shape during a normal indentation load has been performed. Three parameters are

Table 1

Identified parameters for the shell elements.

\begin{tabular}{llllll}
\hline Shell elasticity & \multicolumn{3}{c}{$\begin{array}{l}\text { In-plane shear } \\
\text { plasticity }\end{array}$} & \multicolumn{2}{l}{ Shell damage } \\
\hline$E^{m}(\mathrm{MPa})$ & 4500 & $G_{12}(\mathrm{MPa})$ & 2500 & $Y_{0}(\mathrm{~J})$ & 1.5 \\
$E^{b}(\mathrm{MPa})$ & 52,500 & $\sigma_{0}(\mathrm{MPa})$ & 80 & $Y_{c}(\mathrm{~J})$ & 0.4 \\
$G^{s}(\mathrm{MPa})$ & 4000 & $K_{\text {plas }}(\mathrm{MPa})$ & 120 & $\gamma_{\max }^{p}$ & 0.07 \\
$v$ & 0.3 & $\beta$ & 0.5 & & \\
\hline
\end{tabular}


under investigation and correspond to the maximum tension strain of the three types of rod:

- $\varepsilon_{\max }$ for the rods away from crimp regions,

- $\varepsilon_{\max }^{\text {warp }}=p^{\text {warp }} \varepsilon_{\text {max }}$ for the crimp warp rods,

- $\varepsilon_{\text {max }}^{\text {weft }}=p^{\text {weft }} \varepsilon_{\text {max }}$ for the crimp weft rods.

$\varepsilon_{\max }^{\text {warp }}$ and $\varepsilon_{\max }^{\text {weft }}$ can be expressed in a more convenient manner with a percent of $\varepsilon_{\max }: p^{\text {warp }}$ and $p^{\text {weft }}$. Fig. 6 shows the result of this study for three sets of parameters. The case $a$ corresponds to the reference modelling where every rod has the same strain to failure. It leads to a large cross crack induced by two straight line cracks in both warp and weft directions. By decreasing to $20 \%$ the maximum strain of the rods located at the crimp regions (case $b$ ), the cross crack is shortened. Two sinusoidal crack paths are formed in both directions by localising the failure at the crimp regions. At last, the case $c$ demonstrates the possibility to favour one crack path direction by differentiating the maximum strain-to-failure between crimp warp and crimp weft rods.

For the next section, the set of parameters for the maximum strains of the rods is fixed to $\varepsilon_{\max }=0.016, p^{\text {warp }}=0.9$ and $p^{\text {weft }}=0.8$. It corresponds to the best compromise between experimental and numerical results from $(0 / 90)^{\circ}$ tensile test, drop weight test and gas gun test. The identified parameters used for the rod elements are given in Table 2.

\section{Validation and discussion}

In this section, the ability of the model to predict the failure of composite structures is investigated upon two kind of tests: drop weight normal impact and gas gun oblique impact.

\subsection{Drop weight normal impact test}

\subsubsection{Experimental device and numerical modelling of the drop weight} test

The drop weight normal impact test is performed on laminated specimen made of two $(0 / 90)^{\circ}$ plies of 5 -satin carbon fibres (AS4)/ epoxy matrix (913) woven fabrics. The specimen is a square of edge length $100 \mathrm{~mm}$ and of thickness $0.72 \mathrm{~mm}$. It lays on a rigid table containing an open circle window of $50 \mathrm{~mm}$ diameter as illustrated in Fig. 7. The steel impactor has a $20 \mathrm{~mm}$ diameter hemispheric shape and a mass of $2 \mathrm{~kg}$. It impacts the specimen

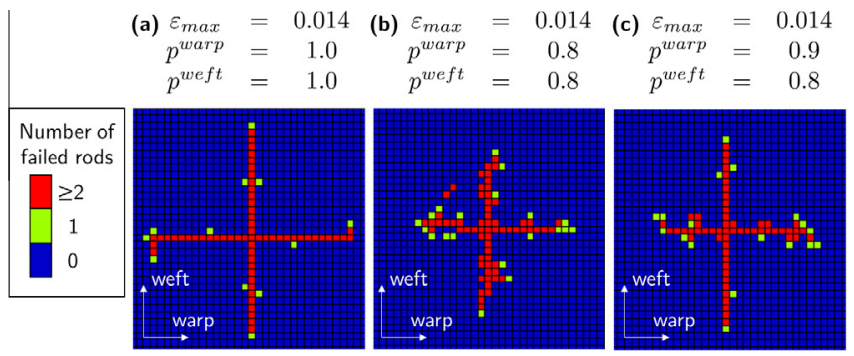

Fig. 6. Rod failure parameters influence upon the fracture shape during a drop weight impact.

Table 2

Identified parameters for the rod elements.

\begin{tabular}{llll}
\hline Rod elasticity & \multicolumn{3}{l}{ Rod failure } \\
\hline Young modulus (MPa) & 120,000 & $\varepsilon_{\max }$ & 0.015 \\
Section area $\left(\mathrm{mm}^{2}\right)$ & 0.106 & $p^{\text {warp }}$ & 0.9 \\
& & $p^{\text {weft }}$ & 0.8 \\
\hline
\end{tabular}

(a) Experimental conditions

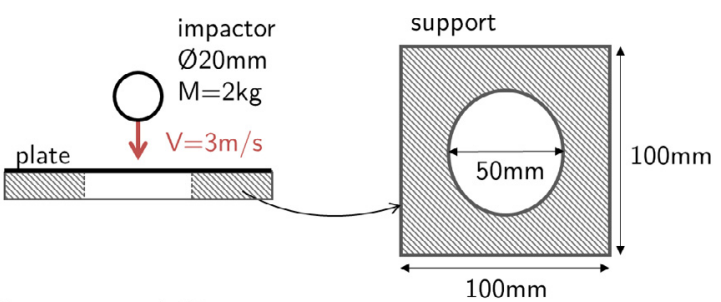

(b) Impact modelling
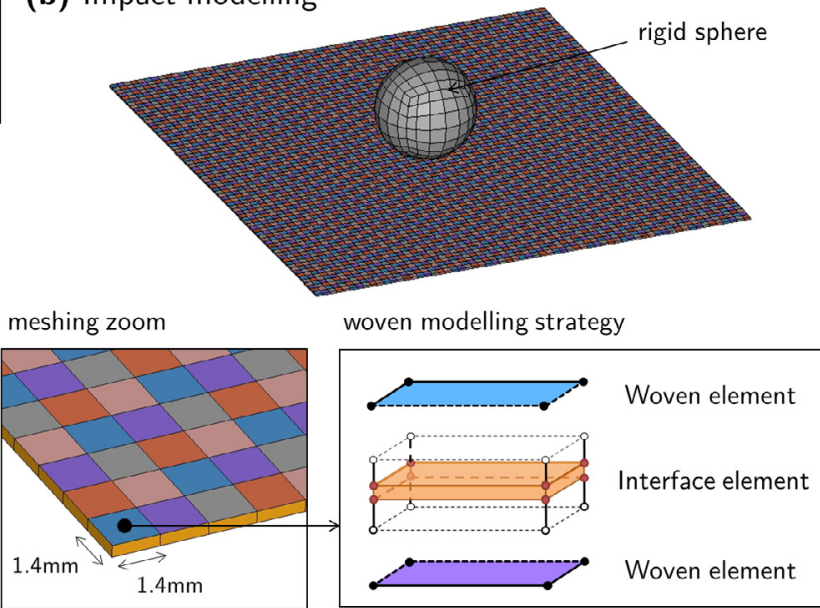

Fig. 7. Drop weight impact test: (a) experimental conditions; (b) modelling of the specimen.

with an initial velocity of $3 \mathrm{~m} / \mathrm{s}$. That is to say an impact energy of $9 \mathrm{~J}$. A load cell, of capacity $120 \mathrm{kN}$, is embedded into the impactor in order to measure the reaction of the specimen and to compute the displacement of the impactor by use of the fundamental principle of dynamics and by double integration. At last, the bottom face of the specimen is recorded with a high-speed digital camera (Photron FastCam APX RS) at a frame rate of 36,000 fps and a resolution of $512 \times 128$ pixels. Three specimens are impacted in order to check the reproducibility of the experimental protocol.

A modelling of this test, relying on the strategy presented in Section 2, is proposed. The specimen involves 14,000 user developed finite elements for a total of 48,000 dofs. The boundary conditions are introduced by the use of a contact between the specimen and a rigid wall. The impactor is a rigid sphere

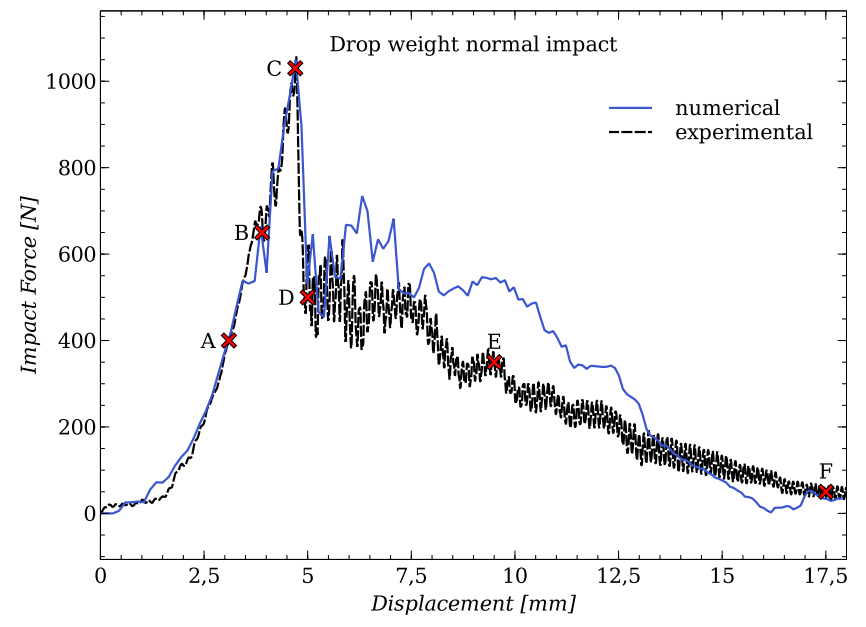

Fig. 8. Load versus displacement curves of drop weight impact test. 
with the adequate mass and initial velocity. The mesh size is $1.4 \times 1.4 \mathrm{~mm}$ in agreement with the measured woven fabric pattern. All the computations are performed with the explicit finite element code RADIOSS on 20 cores from HPC resources. The computational time is about 45 mins.

\subsubsection{Results of drop weight test}

The comparison between the experimental and numerical results is achieved in Figs. 8 and 9. Fig. 8 presents the load versus displacement curves whereas Fig. 9 presents associated damage states. Each damage state is located on the curves by the use of an upper case letter (A, B and so on).

As a first observation, the model gives a satisfactory estimation of the force versus displacement response of the specimen. Although the dissipated energy is slightly over estimated $(19.6 \%$ of relative error), both the two peak forces (points $\mathrm{B}$ and $\mathrm{C}$ )
(6.25\% of relative error) and the final load drop are in good agreement with the experimental data.

The scenario of failure can be deduced from a more detailed analysis.

(1) From the beginning up to point A on the curve, the specimen is subjected to global bending. There is no visible damage on the bottom face of the specimen and the load versus displacement curve rises linearly after an initial adjustment of the whole device.

(2) At point A, the first visible damage occurs at the bottom of the specimen. It corresponds to matrix micro-cracking. The cracks follow the 5-satin weave pattern and tends to separate the bundles of the fabric. At this stage, the model predicts the matrix micro-cracking and a slight debonding between the two plies of the laminate. These two kind of

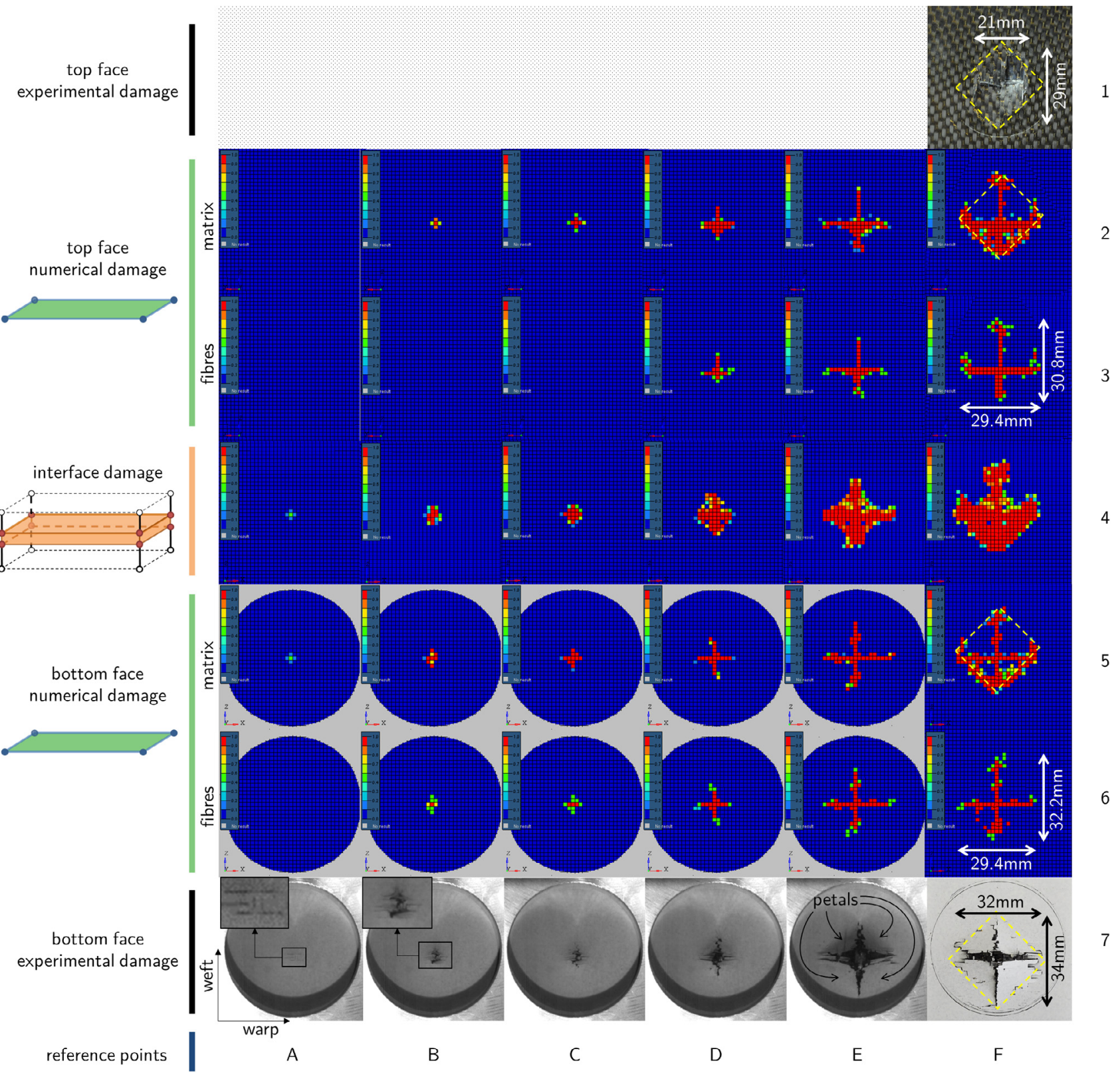

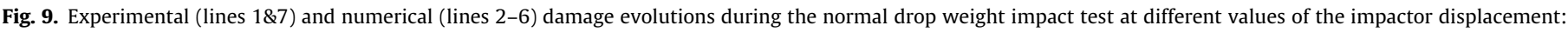
$3.1 \mathrm{~mm}(\mathrm{~A}), 3.9 \mathrm{~mm}(\mathrm{~B}), 4.7 \mathrm{~mm}(\mathrm{C}), 5.0 \mathrm{~mm}(\mathrm{D}), 9.5 \mathrm{~mm}(\mathrm{E})$ and $17.5 \mathrm{~mm}(\mathrm{~F})$. 
damages: matrix micro-cracking and delamination, evolve up to point $B$.

(3) At point B, the response curve exhibits a slight brutal decrease of the load which can be explained by the appearance of the first fibres failure in the bottom ply. As can be seen in Fig. 9, line 7, the crack presents a complex shape, linked to the pattern of the ply. The model also predicts this first warp fibre breakage. It is associated with an increase of the matrix micro-cracking of the bottom ply, of the delamination and with the first matrix micro-cracking in the upper ply.

(4) From point B, the macro crack propagates in the weft direction (warp fibres breakage). It follows a winding path that has the overall shape of a complex line aligned with the 5-satin weave pattern.

(5) At point $C$, a peak force is reached. From point $C$ to point $D$ many events occur in a short time. The main new failure mechanism is the first weft fibres breakage in the bottom ply and the fibres breakage in the upper ply (warp and weft yarns). As a result, a cross crack that involves both plies of the laminate appears. This is well predicted by the model as can be seen in Fig. 9 columns C \& D, lines $3 \& 6$. At this stage, the bending stiffness decreases drastically as can be seen in the load versus displacement curve of Fig. 8. Moreover, all the other damages highlight a significant increase: matrix-micro cracking of both plies, macro-crack of bottom ply and delamination. Once again, the crack of the bottom ply predicted by the model is in very good agreement with the experimental observations (last two lines of Fig. 9).

(6) From points D to E, there is no significant event in the degradation of the specimen. All the damages: matrix microcracking, macro cracks due to fibres breakage and delamination, rise during the penetration of the impactor. The bending of four petals, accompanying the expansion of the cross crack, is clearly visible on the pictures (Fig. 9, column D \& $\mathrm{E}$, line 7).

(7) At point E, a critical state is reached. It corresponds to the full penetration of the impactor that is now clearly visible. At this stage it is worth to notice the ability of the model to give a satisfactory estimate of both the complex shape and the size of the cross crack. However, the bending stiffness of these four petals is a little bit too high which results in an overestimated load in the load versus displacement curve (Fig. 8).

(8) At the end of the test, point F, a new damage is visible on the top and bottom faces of the specimen: a square shaped matrix failure located at the basis of the four petals which is due to the important bending. This degradation phenomenon is predicted with accuracy by the model as can be seen in Fig. 9, column F, lines 1, 2, 5 \& 7. The load level also retrieve a satisfactory level compared with experimental results (Fig. 8).

At the end, the relative errors between experimental and numerical results in terms of crack lengths for the bottom ply is $8.1 \%$ for the warp direction and $5.3 \%$ for the weft direction. For the top ply, the relative errors are $40 \%$ for the warp direction and $6.2 \%$ for the weft direction. The overestimated result for the crack length in the warp direction is due to a 3D effect observed on the experimental fracture surface. Indeed, the macro crack seems to be stopped by a weft yarn and continues through thickness by delamination. Therefore, the model appears to be able to give a satisfactory prediction of the failure scenario and state of the specimen subjected to normal impact.

\subsection{Gas gun oblique impact test}

\subsubsection{Experimental device and numerical modelling of the oblique impact test}

The oblique impact test is performed on a more complex specimen which is a sandwich structure made of two skins of three $(0 / 90)^{\circ}$ plies of the same woven fabric as in Section 4.1.1 separated by a Rohacell $51 \mathrm{~A}$ foam core. The specimen is $200 \mathrm{~mm}$ long and $240 \mathrm{~mm}$ width. Each ply has a thickness of $0.36 \mathrm{~mm}$ and the foam has a thickness of $20 \mathrm{~mm}$. It is simply supported on an inclined table. The impactor is a steel ball of diameter $19 \mathrm{~mm}$ and mass $28 \mathrm{~g}$. It is launched by a gas gun in order to reach the velocity of $90 \mathrm{~m} / \mathrm{s}$ with an angle of $15^{\circ}$ measured from the surface of the upper skin. The testing device is presented in the upper part of Fig. 10. The test is recorded with the same high-speed camera as in Section 4.1.1, under the same conditions. The application of a speckle on the impactor, in conjunction with the use of a digital image correlation algorithm developed at the laboratory [22], enables a fine computation of the velocities of the impactor. The signal is smooth enough to deduce the acceleration of the impactor, and thus the normal impact force $F_{N}$. Some examples of the tracking of the speckled impactor by the DIC algorithm are given in the middle of Fig. 10.

The modelling developed for the simulation of this test reuses the same strategy as presented before for the drop weight normal impact test. There is simply one more ply for the skins. The foam is introduced thanks to the FOAM_PLAS material law from RADIOSS. Its mechanical properties have been identified in previous work $[15,16]$. The impactor is considered to be a rigid body and the table on which it is placed is simply dealt with by a contact on a rigid wall. Some details on the model are shown at the bottom of Fig. 10. At last, the model involves around $1.2 \mathrm{Mdof}$ and is run on a 60 cores parallel computer for a computational time of about 60 mins.

\subsubsection{Results of oblique impact test}

The main results are summarised in Figs. 11 and 12. In Fig. 11, the normal force $F_{N}$ versus time curve is plotted whereas Fig. 12

(a) Experimental conditions

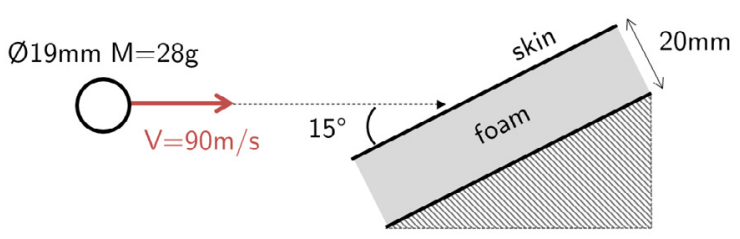

(b) Digital Image Correlation

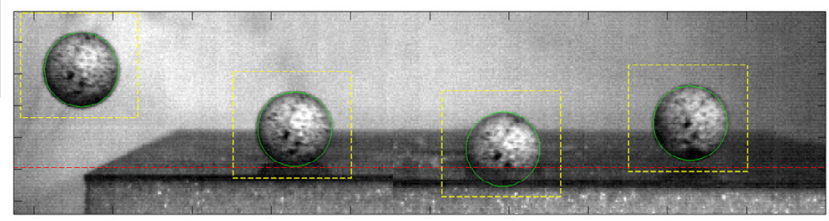

(c) Impact modelling

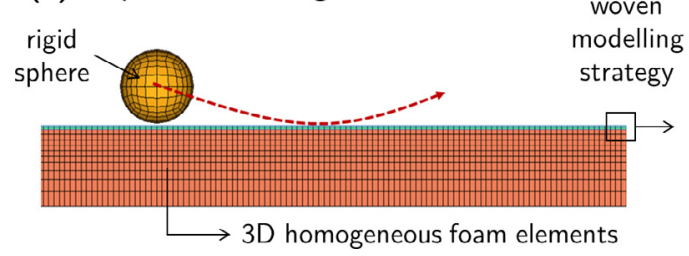

Fig. 10. Oblique impact test: (a) experimental conditions; (b) tracking of the impactor by digital image correlation technique [22]; (c) modelling of the specimen. 


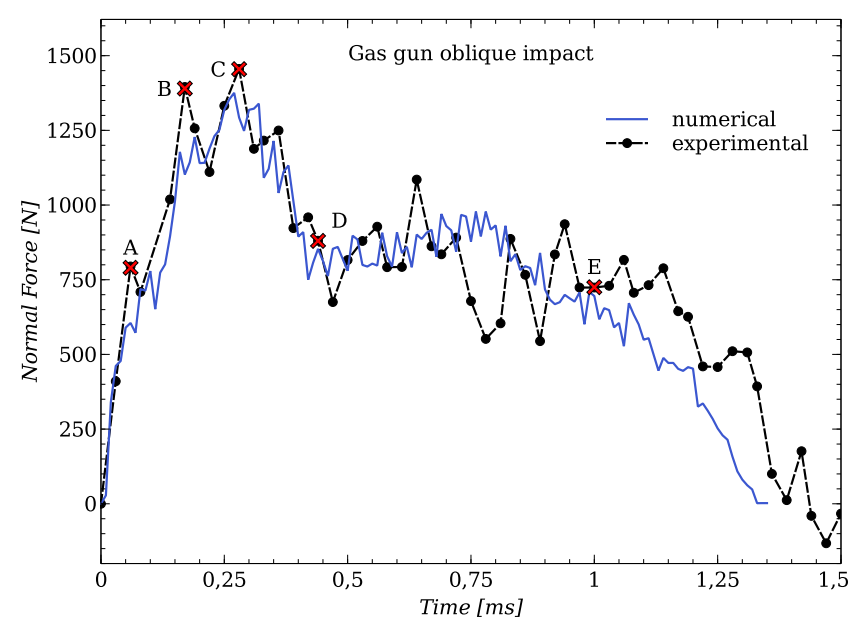

Fig. 11. Load versus time curves of oblique impact test.

presents the experimental and numerical states of the specimen after the impact.

The load versus time curve computed by the model appears to be very close to the measured one during the test. The shape and the level of the two curves are indeed very similar. The relative errors are around $5.5 \%$ on the peak force and $6.1 \%$ on the dissipated energy. Once again, upper case letters are used for the description of the curve. This time, the failure of the specimen is analysed through the model since it gives a fine description of what happens. A comparison of the final states of the specimen obtained numerically and experimentally is finally proposed.

(1) After a short part of elastic loading by bending of the upper skin under the impactor, point $A$ is reached. It corresponds to a macro-crack (fibres breakage) of the bottom ply of the upper skin. This crack is due to the high level of tension seen by the fibres which are orthogonal to the impactor trajectory. The crack is also accompanied by micro-cracks inside the resin. The peak force is visible on both the experimental and numerical curves.

(2) From point A to point B, the damage propagates in the thickness direction. It goes up to reach the two top plies of the skin.

(3) Points B and C reflect the fibres breakages of these two upper remaining plies. After point $\mathrm{C}$, the upper skin is cut on its whole thickness which results in a sudden fail of the load.

(4) From points $C$ to $D$, the impactor penetrates the specimen. The plateau between points $\mathrm{D}$ and $\mathrm{E}$ relates the progress, practically parallel to the upper skin, of the impactor inside the specimen. At this stage, the macro and micro-cracks propagate along the impactor trajectory.

(5) Last step, point E indicates the beginning of the rebound of the impactor. The load decreases to zero, when the contact is broken. This first analysis shows the ability of the model to capture with accuracy the failure events of this complex specimen.

The post impact residual state of the specimen is now presented in Fig. 12 for the upper (left) and bottom (right) plies of the upper skin. The red lines superimposed on the pictures placed at the top of Fig. 12 highlight the macro-cracks corresponding to fibres failure. The orange lines correspond to the micro-cracks (resin cracks) located inside and between the yarns of the woven fabric. A schematic representation of the macro and micro-cracks is given below to illustrate the importance of the 5-harness satin weave pattern on the shape of the cracks.

It is worth to notice the distinct appearances of the damages between the lower and the upper plies. The main macro-crack of the lower ply is clear, with few transverse macro-cracks initiated at some intersections of warp and weft yarns (right column of Fig. 12). This can be explained by the brittle nature of the failure of the fibres and by the protection given by the upper plies. Indeed, the lower ply is not directly in contact with the impactor. The upper ply exhibits a smaller macro-crack surrounded by a rectangular (in white in Fig. 12) shaped diffuse damage whose upper and lower limits are due to the important local friction and bending of

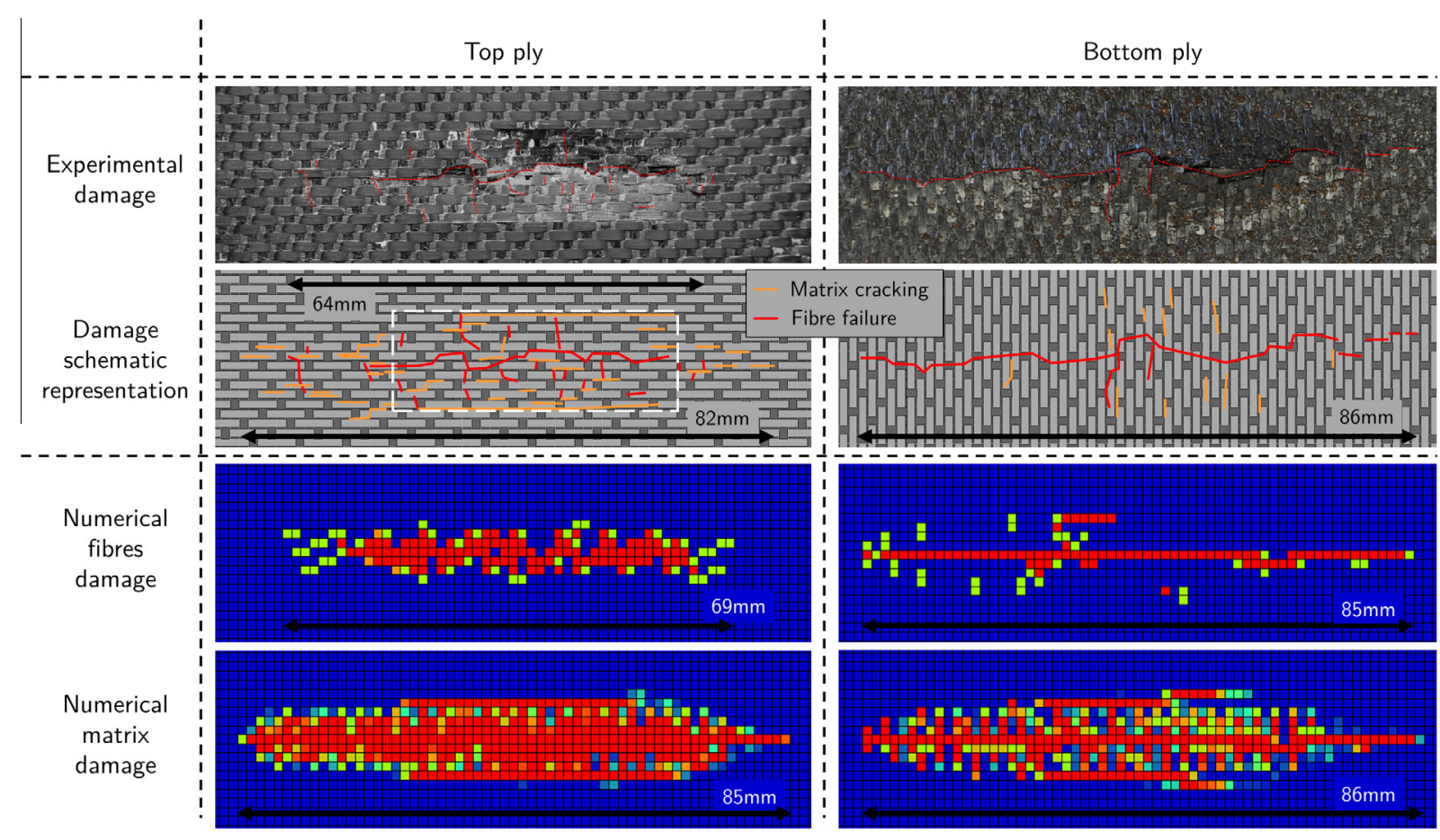

Fig. 12. Experimental (top) and numerical (bottom) damaged specimens after the gas gun oblique impact test. 
the skin in contact with the impactor. This ply, directly in contact with the impactor, suffers from a more important matrix damage as illustrated by the orange lines. They are in accordance with the bleached white appearance of the yarns in the upper left picture of Fig. 12.

\subsection{Discussion}

To conclude this section dedicated to the validation of the proposed model, it can be said that on both kind of tests: drop weight normal impact and gas gun oblique impact tests, the model is in good agreement with experimental observations. The predictions of the load during the tests is coherent with the measures in terms of magnitude and time scale. Moreover, a close look at the failure mechanisms highlights the satisfactory behaviour of the model which seems able to distinguish between the various different failure phenomena that are: fibre breakage, resin micro-cracking and delamination. At last, the introduction of the 5-harness satin weave pattern inside the model, by adequate failure strains at the intersections of warp and weft tows, improves the capability of the model to catch the macro-cracks bifurcations evidenced by the experimental tests.

\section{Conclusion}

A 2D modelling of the 5-harness satin woven composite material has been presented in this paper. A modelling strategy based on the semi-continuous approach and at the woven pattern mesh scale is used. Bundles of fibres are represented with rod elements and matrix is modelled with a damageable shell element.

In order to be more in agreement with experimental observations, two main improvements have been carried out from the original modelling presented in [15]. First, a work on the shell damage has been performed to represent the typical matrix cracks observed during a drop weight impact test. Then, an original approach has been conducted in order to take into account the damage initiation (stress concentrations) at the crimp regions. Indeed, instead of modelling the waviness of the bundles which would inevitably lead to more expensive computational cost, the idea was to lowering the strain to failure of the rods located at the crimp regions.

Comparisons with experimental data from drop weight tests and gas gun tests show good accuracy in the force history and damage size and shape (Figs. 9 and 12). The modelling strategy allows to catch the complex macro-crack path observed experimentally and also the resin micro-cracking and delamination.

This 2D-modelling allows to model a 5-harness satin woven fabric material but is currently developed in order to allow the simulation of a 8-harness satin woven fabric.

\section{Acknowledgement}

The authors acknowledge the supercomputing centre CALMIP for granting access to the HPC resources under the allocation 2015-P09105.

\section{References}

[1] Abrate S. Impact on laminate composites, recent advances. Appl Mech 1997;47:517-44.

[2] Abrate S. Impact on composite structures. Cambridge University Press; 1998.

[3] Lomov SV, Ivanov DS, Truong TC, Verpoest I, Baudry F, Vanden Bosche K, Xie H. Experimental methodology of study of damage initiation and development in textile composites in uniaxial tensile test. Compos Sci Technol 2008;68 (12):2340-9.

[4] Melro AR. Analytical and numerical modelling of damage and francture of advanced composites, Thesis manuscript - University of Porto; 2011.

[5] Daggumati S, Voet E, Van Paepegem W, Degrieck J, Xu J, Lomov SV, Verpoest I. Local strain in a 5-harness satin weave composite under static tension: Part I. Experimental analysis. Compos Sci Technol 2011;71(8):1171-9.

[6] Nilakantan G, Keefe M, Wetzel ED, Bogetti TA, Gillespie Jr JW. Effect of statistical yarn tensile strength on the probabilistic impact response of woven fabrics. Compos Sci Technol 2012;72(2):320-9.

[7] Iannucci L, Willows M. An energy based damage mechanics approach to modelling impact onto woven composite materials - Part I: Numerical models. Compos Part A Appl Sci Manuf 2006;37(11):2041-56.

[8] Iannucci L, Willows M. An energy based damage mechanics approach to modelling impact onto woven composite materials: Part II. Experimental and numerical results. Compos Part A Appl Sci Manuf 2007;38(2):540-54.

[9] Iannucci L. Progressive failure modelling of woven carbon composite under impact. Int J Impact Eng 2006;32(6):1013-43.

[10] Cousigné O, Moncayo D, Coutellier D, Camanho P, Naceur H, Hampel S. Development of a new nonlinear numerical material model for woven composite materials accounting for permanent deformation and damage. Compos Struct 2013;106:601-14.

[11] Cousigné O, Moncayo D, Coutellier D, Camanho P, Naceur H. Numerical modeling of nonlinearity, plasticity and damage in CFRP-woven composites for crash simulations. Compos Struct 2014;115:75-88.

[12] Johnson A, Pickett A, Rozycki P. Computational methods for predicting impact damage in composite structures. Compos Sci Technol 2001;61(15):2183-92.

[13] Johnson A. Modelling fabric reinforced composites under impact loads Compos Part A Appl Sci Manuf 2001;32(9):1197-206.

[14] Navarro P, Aubry J, Marguet S, Ferrero J-F, Lemaire S, Rauch P. Experimental and numerical study of oblique impact on woven composite sandwich structure: influence of the firing axis orientation. Compos Struct 2012;94 (6):1967-72.

[15] Navarro P, Aubry J, Marguet S, Ferrero J-F, Lemaire S, Rauch P. Semi-continuous approach for the modeling of thin woven composite panels applied to oblique impacts on helicopter blades. Compos Part A Appl Sci Manuf 2012;43 (6):871-9.

[16] Navarro P, Pascal F, Aubry J, Marguet S, Ferrero JF, Lemaire S, Rauch P. Semicontinuous approach for the study of impacts on woven composite laminates: modeling interlaminar behavior with a specific interface element. Int J Impact Eng 2015;75:184-93.

[17] Daggumati S, Van Paepegem W, Degrieck J, Xu J, Lomov SV, Verpoest I. Local damage in a 5-harness satin weave composite under static tension: Part II Meso-FE modelling. Compos Sci Technol 2010;70(13):1934-41.

[18] Melro AR, Camanho PP, Andrade Pires FM, Pinho ST. Numerical simulation of the non-linear deformation of 5-harness satin weaves. Comput Mater Sci 2012;61:116-26.

[19] Obert E, Daghia F, Ladevze P, Ballere L. Micro and meso modeling of woven composites: transverse cracking kinetics and homogenization. Compos Struct 2014;117:212-21.

[20] Zako M, Uetsuji Y, Kurashiki T. Finite element analysis of damaged woven fabric composite materials. Compos Sci Technol 2003;63(34):507-16.

[21] Batoz JL, Dhatt G. Modélisation des structures par éléments finis: coques, hermes edition, vol. 3. Paris; 1992.

[22] Passieux J-C, Navarro P, Périé J-N, Marguet S, Ferrero J-F. A digital image correlation method for tracking planar motions of rigid spheres: application to medium velocity impacts. Exp Mech 2014;54(8):1453-66. 